\title{
EFFECT OF SURFACE CHEMICALS ON INTRAGUILD PREDATION OF EGGS OF TWO APHIDOPHAGOUS LADYBEETLES, Coccinella undecimpunctata L., AND Cydonia visina ISIS CR. (COLEOPTERA: COCCINELLIDAE) Abdel-Salam, A. H. ${ }^{1}$; A. A. Ghanim ${ }^{1}$; M. E. El-Naggar ${ }^{2}$ and Wessam Z. A. Bessadah ${ }^{2}$ \\ ${ }^{1}$ Economic Entomology Dept., Fac. Agric., Mans. Univ., Mans. 35516, Egypt \\ ${ }^{2}$ Plant Protection Res. Inst., Agric. Res. Center, Ministry of Agric., Giza, Egypt \\ E-mail: adhabdelus@yahoo.com
}

\begin{abstract}
Intraguild predation (IGP) on egg and the role of surface chemicals in two aphidophagous coccinellids species, $C$. undecimpunctata and $C$. visina isis were examined. The first instar larvae of both species prefer to eat washed heterospecific eggs than unwashed eggs. Surface chemicals appear to play a major role for the preference of washed eggs, as the ladybeetle behavior was reversed when these chemicals were remained. The surface chemicals present on the eggs appears to reduce intraguild predation. The green lacewing, Chrysoperla carnea (Stephens) in its first instar consumed $C$. undecimpunctata and $C$. visina isis eggs without showing any preference for either washed or unwashed treatments, although we observed that the washed eggs were eaten more than those unwashed. The average number of coccinellid eggs consumed by the first instar larvae of other predator species was determined and the results are discussed.
\end{abstract}

\section{INTRODUCTION}

The first instar larvae of aphidophagous coccinellids (Coleoptera: Coccinellidae) are under strong selection pressure to find food soon after hatching. They can readily eat unhatched or late hatched eggs of their own batches due to the presence of trophic eggs and asynchronous egg hatching (Osawa, 1992). The eggs of certain aphidophagous ladybirds, viz. Coccinella septempunctata L. may be protected against non-sibling cannibalism and heterospecific predation (Hemptinne et al., 2000b). However, eggs of certain species can readily be victimized by hungry ladybeetles.

Eggs are generally assumed to be highly nutritious with yolk being a rich protein source for developing embryonic larvae. They are, therefore, a high quality food source meeting the nutritional requirements of the neonates better than alternative prey (Gagne et al., 2002).

The same egg can be nutritive to one ladybird species while toxic to the other (Hemptinne et al., 2001; Burgio et al., 2002; Santi et al., 2003). If neonates possess the ability to discriminate amongst their prey (Gagne et al., 2002), it is expected that they would selectively consume the more suitable food: unrelated conspecific or heterospecific eggs. Keeping in view the nutritional benefits of conspecific eggs (Snyder et al., 2000). 
Chemicals present on the surface of eggs may also influence the cannibalism and predation by later larval instars and adults (Agarwala and Dixon, 1993; Hemptinne et al., 2000b, 2001). They play a major role in attraction/repulsion of predators and have relative costs and benefits on predator's fitness (Hemptinne et al., 2001). The removal of these chemicals may negate the ability to discriminate amongst conspecific and heterospecific eggs result in random predation of eggs. Clustering of eggs is common in aphidophagous ladybirds (Agarwala and Dixon, 1993). Egg clustering might increase an individual's chance of avoiding predatory attacks (Kiltie, 1980). Clustered eggs may have aposematic properties, deterring intraguild predation (IGP) (Agarwala and Dixon, 1993) and non-sibling cannibalism (Agarwala et al., 1997).

Eggs and younger larvae are more vulnerable to cannibalism by older larvae than vice versa (Agarwala and Dixon, 1992). Similarly, in intraguild predation, a small species is more likely to be the intraguild prey of a large species (Sengonca and Frings, 1985; Lucas et al., 1998; Phoofolo and Obrycki, 1998; Hindayana et al., 2001). However, in species of ladybird that have overlapping habitat preferences, small species, such as Adalia bipunctata L. are more toxic to large species, such as $C$. septempunctata, and this reduces the incidence of the small species being eaten by the large species (Agarwala and Dixon, 1992; Agarwala et al., 1998; Hemptinne et al., 2000a). Thus, vulnerable species may be protected chemically from intraguild predation.

Within the community, predation risk of individuals may dependent upon factors such as their mobility and the semiochemicals (allomones) that they produce as demonstrated in Coccinellidae (Felix and Soares, 2004; Omkar et al., 2004). However, Hemptinne et al. (2000b) found that some alkaloids are present in $A$. bipunctata and $C$. septempunctata eggs, which may contribute to reducing intraguild predation as in other ladybird species (Omkar et al., 2004).

All stages of ladybeetle contain similar concentrations of alkaloids (Pasteels et al., 1973) that are thought to be responsible for their toxicity. Eggs and hatching larvae are relatively easy to obtain compared to other developmental stages. Therefore, in this study, IGP by hatching ladybeetle and Chrysopid larvae fed eggs of other species were determined to examine interspecific egg predation among predator species and the egg toxicity effect of two ladybeetles, $C$. undecimpunctata and $C$. visina isis on the incidence of predation between these species.

\section{MATERIALS AND METHODS}

To obtain eggs, pairs of adults were kept in plastic Petri dishes $(9 \mathrm{~cm}$ in diameter), each containing a piece of filter paper, and fed daily with aphids, Aphis craccivora Koch. Any eggs laid on the filter paper were removed and placed in other Petri dishes (9 cm in diameter).

To evaluate the effect of surface alkanes on IGP in different predators, two clusters of C. undecimpunctata eggs were individually in Petri 
dishes $(9 \mathrm{~cm}$ in diameter), the first cluster contained freshly laid eggs and the second were washed in $n$-hexane for two minutes to remove the surface alkanes and dried using a filter paper. Hexane was chosen as a solvent because a preliminary study indicated that it does not penetrate eggs during two minutes extraction period, but only removes chemicals present on the egg surface (Chan, 1995).

A six hours starved first instar larvae of $C$. visina isis and $C$. carnae were introduced individually into Petri dishes which containing treated (surface washed eggs) and untreated (freshly laid eggs) clusters of $10 \mathrm{C}$. undecimpunctata eggs. Each treatment (washed or unwashed) was replicated 10 times. The experiment was conducted under laboratory conditions at $28.0 \pm 2.0^{\circ} \mathrm{C}, 75.0 \pm 5 \% \mathrm{RH}$ and photoperiod of $14 \mathrm{~L}$ : $10 \mathrm{D}$. The first instar larva of the two species was allowed to feed separately on eggs and observations on egg IGP were taken after $24 \mathrm{~h}$. After $24 \mathrm{~h}$, the larvae were removed and the number of egg consumed was determined by counting the number of remaining and left over eggs.

In the same way, the experiment was repeated using eggs of $C$. visina isis, both treated (surface washed eggs) and untreated (unwashed eggs), and with the first instar larvae of $C$. undecimpunctata and $C$. carnae as IG predators.

\section{Data analysis:}

The data of the average number of washed or unwashed eggs consumed were subjected for one way analysis of variance (ANOVA), and the means were separated using Duncan's Multiple Range Test (Costat Software, 2004).

\section{RESULTS AND DISCUSSION}

To examine chemical protection of ladybeetle eggs, the reluctance of larvae to eat the eggs of other species of ladybeetle was determined. The average number of coccinellid eggs consumed by the first instar larvae of other species is given in (Figures 1 and 2).

After 24 hours, the consumption of $C$. undecimpunctata eggs by the first instar larvae of $C$. vivina isis varied significantly between the two washed and unwashed treatments (Table 1). Average numbers of washed and unwashed eggs fed to larvae were $7.2 \pm 0.49(72 \%)$ and $3.1 \pm 0.23(31 \%)$, respectively (Figure 1). There was a highly significant difference of $C$. vivina isis washed eggs $(7.9 \pm 0.59)$ were consumed compared with unwashed eggs consumed by $C$. undecimpunctata $(4.2 \pm 0.25)$ (Table 2, Figure 2 ). The percentage of $C$. vivina isis unwashed eggs consumed by larvae of $C$. undecimpunctata $(42 \%)$ was significantly lower than percentage of washed consumed eggs (79\%) (Figure 2). In the two species of ladybeetles, larvae preferentially attacked and ate the clusters containing washed heterospecific eggs. The first instar larvae of $C$. undecimpunctata and $C$. vivina isis consumed heterospecific eggs without surface chemicals more than heterospecific eggs containing surface chemicals. Thus, chemicals present on the egg surface deter larvae from engaging in IGP. Agarwala and Dixon 
Abdel-Salam, A. H. et al.

(1992) reported reluctance by the coccinellids, $A$. bipunctata and $C$ septempunctata to eat eggs of the other species.

Table 1. One way analysis of variance (ANOVA) for the effects of IGP on eggs of $C$. undecimpunctata washed or unwashed in $\mathrm{n}$ - hexan by the first instar larvae of $C$. vivina isis after $24 \mathrm{~h}$ under laboratory condition.

\begin{tabular}{|c|c|c|c|c|c|}
\hline Source & SS & df & MS & F & P \\
\hline Mean effects & 84.05 & 1 & 84.05 & 57.09 & $0.000^{\text {** }}$ \\
\hline Error & 26.5 & 18 & 1.472 & - & - \\
\hline Total & 110.55 & 19 & - & - & - \\
\hline
\end{tabular}

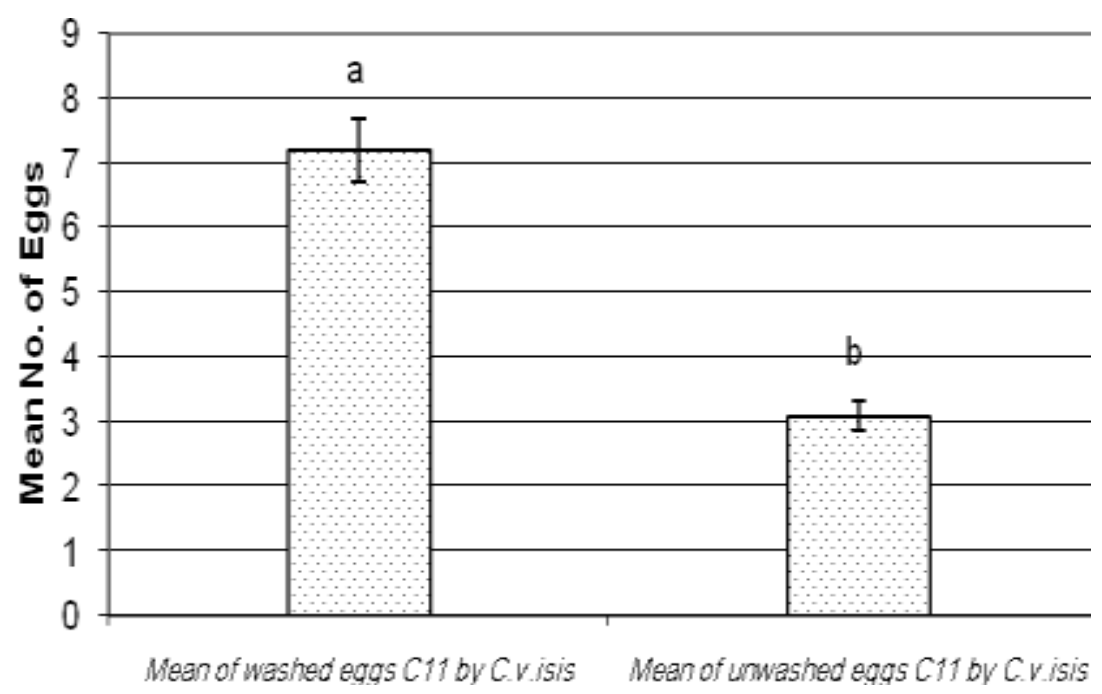

Figure 1. Mean numbers \pm SEM of washed or unwashed $C$. undecimpunctata eggs consumed by the first instar larvae of $C$. vivina isis after $24 \mathrm{~h}$ under laboratory conditions. Means followed by the same small letter are not significantly different at the $1 \%$ level of probability (Duncan's Multiple Range Test).

Table 2. One way analysis of variance (ANOVA) for the effects of IGP on eggs of $C$. vivina isis washed or unwashed in $\mathrm{n}$ - hexan by the first instar larvae of $C$. undecimpunctata after $24 \mathrm{~h}$ under laboratory condition.

\begin{tabular}{|c|c|c|c|c|c|}
\hline Source & SS & df & MS & F & P \\
\hline Mean effects & 68.45 & 1 & 68.45 & 33.76 & $0.000^{\text {** }}$ \\
\hline Error & 36.5 & 18 & 2.028 & - & - \\
\hline Total & 104.95 & 19 & - & - & - \\
\hline
\end{tabular}




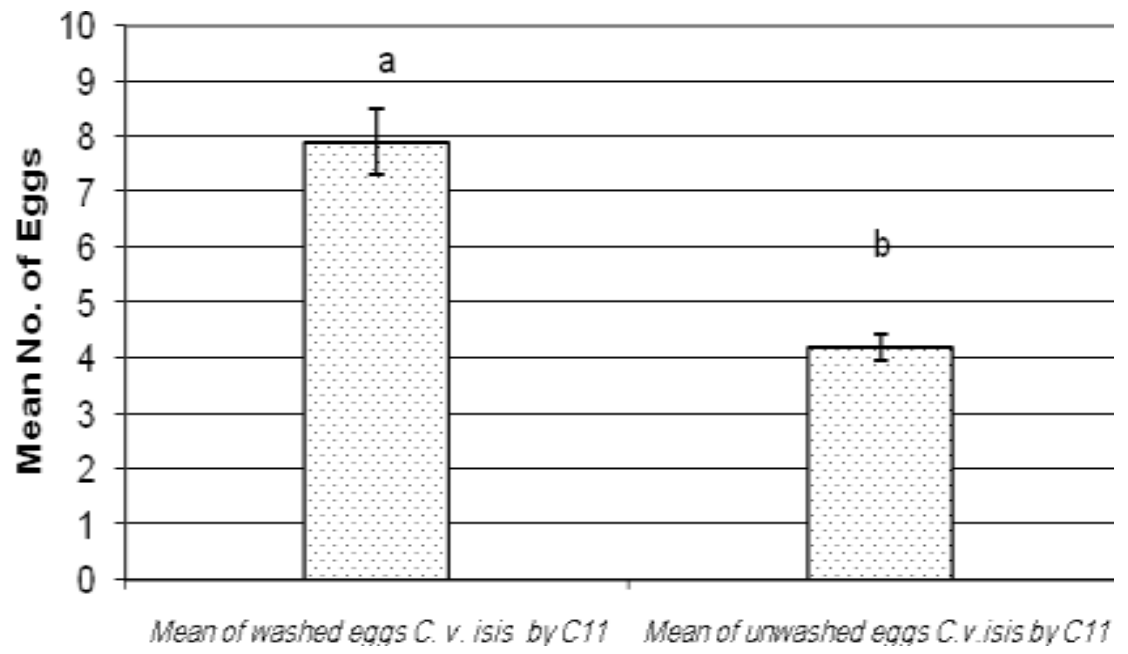

Figure 2. Mean numbers \pm SEM of washed or unwashed $C$. vivina isis eggs consumed by the first instar larvae of C.undecimpunctata after $24 \mathrm{~h}$ under laboratory conditions. Means followed by the same small letter are not significantly different at the $1 \%$ level of probability (Duncan's Multiple Range Test).

In ladybeetles, it seems that surface chemistry of heterospecific eggs might be less effective between species. Insect eggs are rich in cholesterols (MacDonald et al., 1990) and it appears that the egg cholesterols are species-specific. Surface chemistry of different insects varies (Carlson et al., 1999; Nielsen et al., 1999) and is thus likely to be more similar within than between species. Hemptinne et al. (2000a) suggest it is highly unlikely that coccinellid larvae would encounter sufficient numbers of coccinellid eggs (e.g., for predation and/or cannibalism) in the field to complete development from first instar to adult.

After 24 hours, the first instar larvae of $C$. carnae attacked a higher percentage of all washed and unwashed eggs of C.undecimpunctata $\{8.1 \pm$ $0.57(81 \%)$ and $6.9 \pm 0.23(69 \%)$, respectively\} (Table 3, Figure 3) compared with the percentage of eggs attacked by ladybeetles larvae.

Table 3. One way analysis of variance (ANOVA) for the effects of IGP on eggs of $C$. undecimpunctata washed or unwashed in $\mathrm{n}$ - hexan by the first instar larvae of $C$. carnae after $24 \mathrm{~h}$ under laboratory condition.

\begin{tabular}{|c|c|c|c|c|c|}
\hline Source & SS & df & MS & F & P \\
\hline Mean effects & 7.2 & 1 & 7.2 & 3.83 & $0.0569 \mathrm{~ns}$ \\
\hline Error & 33.8 & 18 & 1.88 & - & - \\
\hline Total & 41 & 19 & - & - & - \\
\hline
\end{tabular}


Abdel-Salam, A. H. et al.

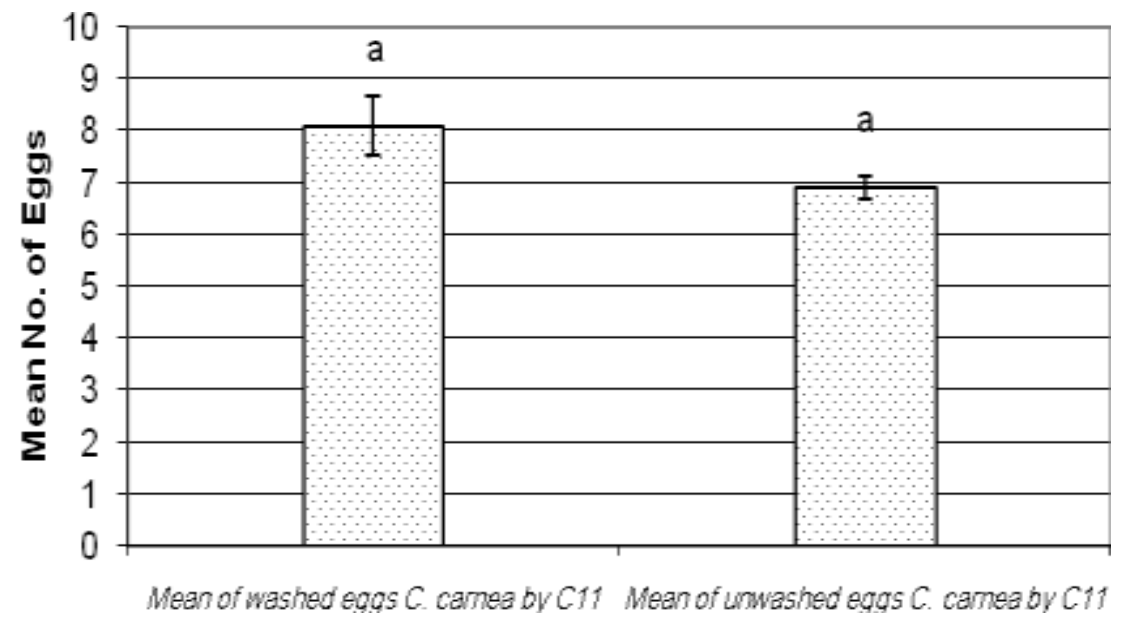

Figure 3. Mean numbers \pm SEM of washed or unwashed $C$. undecimpunctata eggs consumed by the first instar larvae of $C$. carnae after $24 \mathrm{~h}$ under laboratory conditions. Means followed by the same small letter are not significantly different at the $1 \%$ level of probability (Duncan's Multiple Range Test).

There were $8.4 \pm 0.45(84 \%)$ and $7.5 \pm 0.17(75 \%)$ of $C$. vivina isis washed and unwashed eggs consumed by the first instar larvae of $C$. carnae respectively, after 24 hours (Table 4, Figure 4). The percentage of egg consumed by larvae of $C$. carnae was high but not significantly different between the two washed and unwashed treatments. Thus, $C$. carnae is likely to have a negative impact upon this coccinellid species through intraguild egg predation, especially when aphid populations decline.

The toxicity of eggs not only varies among ladybeetle species but also the impact of that toxicity on the intraguild predator varies across species. One hypothesis that this variation reflects the degree and intensity with which any two species may interact through intraguild predation (Sato and Dixon, 2004).

The mouthparts of $C$. carnea larvae and Orius laevigatus (Fieber) nymphs and adults allow these species to perforate the egg chorion, and then suck the contents from the egg. If the chorion of a ladybird egg was broken by the mouthparts of the lacewing larva, this stopped the development of the embryo (Santi and Maini, 2006). Intraguild predation has the potential to be a major source of egg mortality among ladybirds, and chemical defense of eggs appears important often in reducing the incidence of such intraguild predation (Agarwala and Dixon, 1992 \& 1993; Yasuda and Shinya, 1997; Schellhorn and Andow, 1999; Hemptinne et al. 2000 a \& b; Agarwala and Yasuda, 2001; Sato and Dixon, 2004; Cottrell, 2004 \& 2005). 
Table 4. One way analysis of variance (ANOVA) for the effects of IGP on eggs of $C$. vivina isis washed or unwashed in $\mathrm{n}$ - hexan by the first instar larvae of $C$. carnae after $24 \mathrm{~h}$ under laboratory condition.

\begin{tabular}{|c|c|c|c|c|c|}
\hline Source & SS & df & MS & F & P \\
\hline Mean effects & 4.05 & 1 & 4.05 & 3.49 & $0.0782 \mathrm{~ns}$ \\
\hline Error & 20.9 & 18 & 1.16 & - & - \\
\hline Total & 24.95 & 19 & - & - & - \\
\hline
\end{tabular}

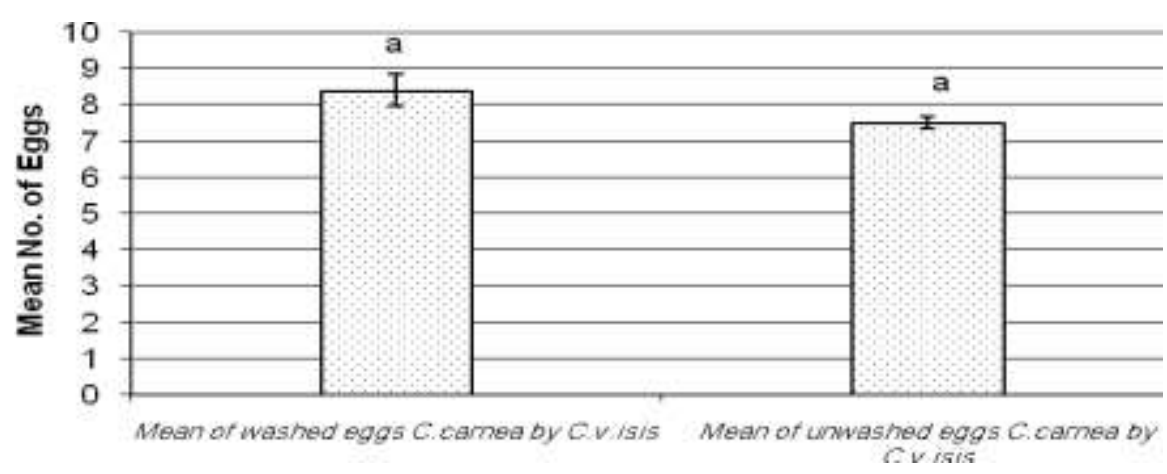

Figure 4. Mean numbers \pm SEM of washed or unwashed $C$. vivina isis eggs consumed by the first instar larvae of $C$. carnae after $24 \mathrm{~h}$ under laboratory conditions. Means followed by the same small letter are not significantly different at the $1 \%$ level of probability (Duncan's Multiple Range Test).

\section{REFERENCES}

Agarwala, B. K. and Dixon, A.F.G. (1992). Laboratory study of cannibalism and interspecific predation in ladybirds. Ecol. Entomol., 17: 303-309.

Agarwala, B. K. and Dixon, A. F. G. (1993). Why do ladybirds lay eggs in cluster? Funct. Ecol., 7: 541-548.

Agarwala, B. K.; Bhattacharya, S. and Bardhanroy, P. (1997). Cluster laying of eggs does not increase the risk of cannibalism by first instar larvae in ladybird beetles. Proc. Indian Natn. Sci. Acad., 63B: 1-9.

Agarwala, B. K.; Bhattacharya, S. and Bardhanroy, P. (1998). Who eats whose eggs? Intra- versus inter-specific interactions in starving ladybird beetles predaceous on aphids. Ethology, Ecology and Evolution, 10: 361-368.

Agarwala, B. K. and Yasuda, H. (2001). Overlapping oviposition an chemical defense of eggs in two co-occurring species of ladybird predators of aphids. J. Ethol., 19: 47-53.

Burgio, G.; Santi, F. and Maini, S. (2002). On intra-guild predation and cannibalism in Harmonia axyridis (Pallas) and Adalia bipunctata L. (Coleoptera: Coccinellidae). Biol. Control, 24: 110-116. 
Carlson, D. A.; Geden, C. J. and Bernier, U. R. (1999). Identification of pupal exuviae of Nasonia vitripennis and Muscidifurx raptorellus parasitoids using cuticular hydrocarbons. Biol. Cont., 15, 97-106.

Chan, F. Y. (1995). Etude des alcaloides des Adalia bipunctata (L.) en relation avec le comportement de l'insects. MSc thesis. Facultae univesitaire des Sciences agronomiques, Gembloux, Belgium, p. 71.

CoStat Software. (2004). CoStat. www.cohort.com. Monterey, California, USA.

Cottrell, T. (2004). Suitability of exotic and native lady beetle eggs (Coleoptera: Coccinellidae) for development of lady beetle larvae. Biol. Control, 31: 362-371.

Cottrell, T. (2005). Predation and cannibalism of lady beetle eggs by adult lady beetles. Biol. Control, 34: 159-164.

Felix, S. and Soares O. A., (2004). Intraguild predation between the aphidophagous ladybird beetles Harmonia axyridis and Coccinella undecimpunctata (Coleoptera: Coccinellidae): the role of body weight. Euro. J. Entomol., 101: 237-242.

Gagne, I.; Coderre, D. and Mauffette, Y. (2002). Egg cannibalism by Coleomegilla maculata Lengi neonates: preference even in the presence of essential prey. Ecol. Entomol., 27: 285-291.

Hemptinne, J. L.; Dixon, A.F.G. and Gauthier, C. (2000a). Nutritive cost of intraguild predation on eggs of Coccinella septempunctata and Adalia bipunctata (Coleoptera: Coccinellidae). Euro. J. Entomol., 97: 559562.

Hemptinne, J. L.; Lognay, G.; Gauthier, C. and Dixon, A. F. G. (2000b). Role of surface chemicals signals in egg cannibalism and intraguild predation in ladybirds (Coleoptera: Coccinellidae). Chemoecology, 10: 123-128.

Hemptinne, J. L.; Lognay, G.; Doumbia, M. and Dixon, A. F. G. (2001). Chemical nature and persistence of the oviposition deterring pheromone in the tracks of the larvae of the two spot ladybird, Adalia bipunctata (Coleoptera: Coccinellidae). Chemoecology, 11: 43-47.

Hindayana, D.; Meyhofer, R.; Scholz, D. and Poehling, H.M. (2001). Intraguild predation among the hoverfly Episyrphus balteatus de Geer (Diptera: Syrphidae) and other aphidophagous predators. Biol. Control, 20: 236246.

Kiltie, R. A. (1980). Application to the search theory to the analysis of prey aggregation as an antipredaptic tactics. J. Theo. Biol., 87: 201-206.

Lucas, E.; Coderre, D. and Brodeur, J. (1998). Intraguild predation among aphid predators: characterization and influence of extraguild prey density. Ecology, 79: 1084-1092.

MacDonald, D. L.; Nham, D. N.; Cochran, W. K. and Ritter, K. S. (1990). Differences in the sterol composition of Heliothes zea fed Zea mays versus Medicago sativa. Insect Biochem., 20: 437-442.

Nielsen, J.; Boomsma, J. J.; Oldham, N. J.; Petersen, H. C. and Morgan, E. D., (1999). Colony-level and seasonal-specific variation in cuticular hydrocarbons profiles of individual workers in the ant Formica truncorum. Insectes Sociaux, 46: 58-65. 
Omkar; Pervez, A. and Gupta, A. K. (2004). Role of surface chemicals in egg cannibalism and intraguild predation by neonates of two aphidophagous ladybirds, Propylaea dissecta and Coccinella transversalis. J. Appl. Ent., 128: 691-695.

Osawa, N. (1992). Sibling cannibalism in the ladybird beetle Harmonia axyridis: fitness consequences for mother and offspring. Res. Pop. Ecol., 34: 45-55.

Pasteels, J. M.; Deroe, C.; Tursch, B.; Braekman, J. C.; Daloze, D. and Hootele, C. (1973). Distribution et activites des alcalod'des defensifs des Coccinellidae. J. Insect Physiol., 19: 1771-1784.

Phoofolo, M.W. and Obrycki, J.J. (1998). Potential for intra-guild predation and competition among predatory Coccinellidae and Chrysopidae. Ent. Exp. Appl., 89: 47-55.

Santi, F. and Maini, S. (2006). Predation upon Adalia bipunctata and Harmonia axyridis eggs by Chrysoperla carnea larvae and Orius laevigatus adults. Bull. Insectol., 59 (1): 53-58.

Santi, F.; Burgio, G. and Maini, S. (2003). Intra-guild predation and cannibalism of Harmonia axyridis and Adalia bipunctata in choice conditions. Bull. Insectol., 56: 207-210.

Sato, S. and Dixon, A. F. G. (2004). Effect of intraguild predation on the survival and development of three species of aphidophagous ladybirds: consequences for invasive species. Agric. \& Forest Entomol., 6: 21-24.

Schellhorn, N.A. and Andow, D.A. (1999). Cannibalism and interspecific predation: role of oviposition behavior. Ecol. Appl., 9: 418-428.

Sengonca, C. and Frings, B. (1985). Interference and competitive behaviour of the aphid predators, Chrysoperla carnea and Coccinella septempunctata in the laboratory. Entomophaga, 30: 245-251.

Snyder, W. E.; Joseph, S. B.; Preziosi, R. F. and Moore, A. J. (2000). Nutritional benefits of cannibalism for the lady beetle Harmonia axyridis (Coleoptera: Coccinellidae) when prey quality is poor. Environ. Entomol., 29: 1173-1179.

Yasuda, H. and Shinya, Y. (1997). Cannibalism and interspecific predation in two predatory ladybirds in relation to prey abundance in the field. Entomophaga, 42: 153-163. 


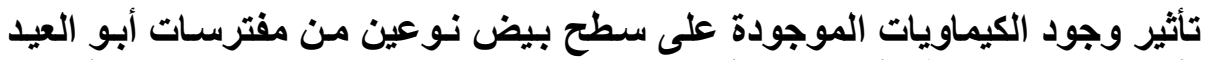

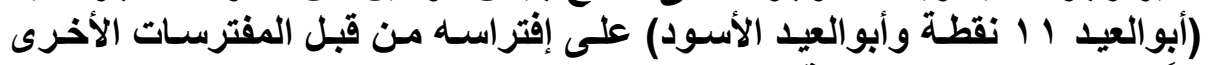
للمَّن تحت الظروف المعملية

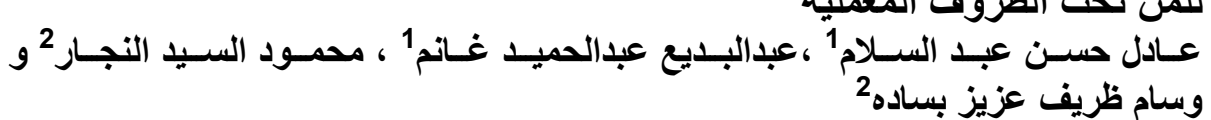

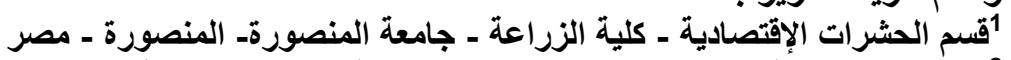

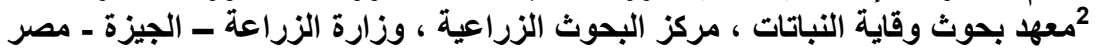

تم دراسة إفتراس بيض كل من أبو العيد 11 نقطة و أبو العيد الإسود من قبل المفترسـات

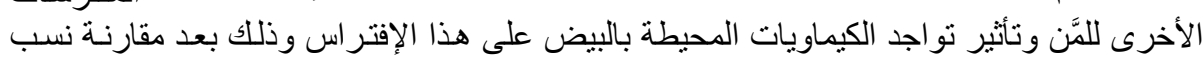

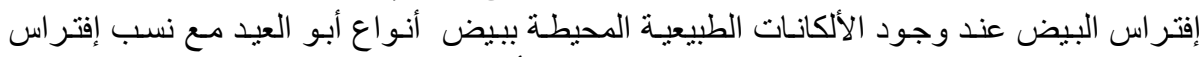

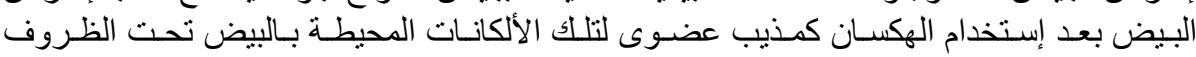
المعطلية.

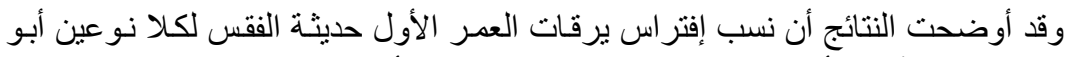

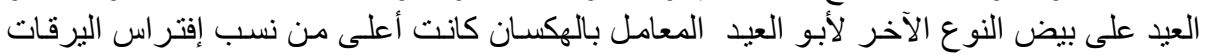

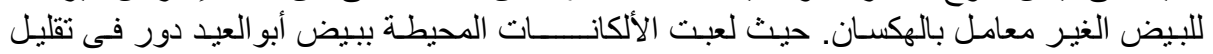

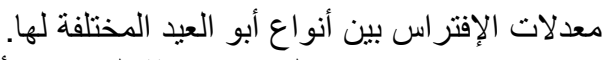

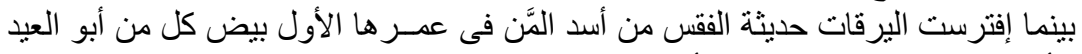

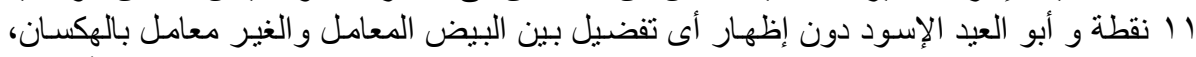

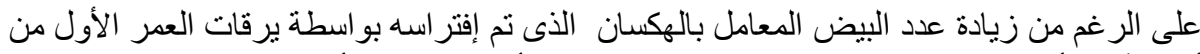

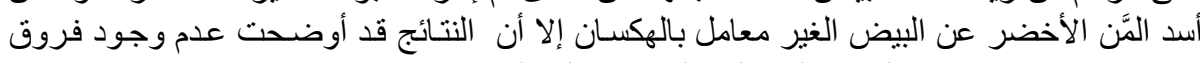
معنوية فى الإفتراس بين البيض المعامل و الغير معامل بالهكسان.

كلية الزراعة - جامعة المنصورة

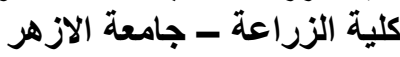

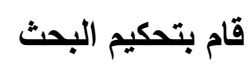

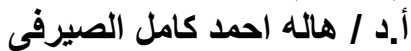
أ.د / الد / حمدى احمد محمد الصنير 